\title{
Avaliação da Sustentabilidade do Instituto Federal de Educação, Ciência e Tecnologia do Rio Grande do Norte
}

http://dx.doi.org/10.21527/2237-6453.2018.45.249-272

Recebido em: $15 / 10 / 2016$

Aceito em: 18/4/2018

Jose Irivaldo Alves Oliveira Silva ${ }^{1}$, Andre Luis Santos Pinheiro

\begin{abstract}
RESUMO
Este trabalho tem como objetivo analisar como se dá o desenvolvimento de uma política de sustentabilidade numa organização pública como o Instituto Federal de Educação, Ciência e Tecnologia do Rio Grande do Norte, por meio da investigação das ações estabelecidas nos seus campi, mensurando, em seguida, seus desempenhos em sustentabilidade. Utilizou-se fonte documental e a aplicação de lista de verificação proposta no Sistema Contábil Gerencial Ambiental - Sicogea 2ª geração. Constatou-se a preocupação da instituição com a redução do consumo e aa produção de resíduo e com sua destinação, assim como com a produção de energia fotovoltaica e ao tratamento e reuso de efluentes líquidos. Por outro lado, os resultados indicam que as ações de sustentabilidade não estão adequadamente articuladas, havendo uma sinalização recente de progresso no sentido de sistematização dessas ações.
\end{abstract}

Palavras-chave: Sustentabilidade. Gestão ambiental. Instituições de ensino. IFRN.

EVALUATION OF SUSTAINABILITY OF THE FEDERAL INSTITUTE OF EDUCATION, SCIENCE AND TECHNOLOGY OF RIO GRANDE DO NORTE

\begin{abstract}
This work aims to analyze how the development of a sustainability policy in a public organization such as the Federal Institute of Education, Science and Technology of Rio Grande do Norte by means of the investigation of the actions implemented in its campuses, performance. We used documentary source and the checklist application that is proposed in the Accounting Environmental Management System - Sicogea (in portuguese) 2nd generation. It was observed the concern of the institution to reduce consumption and waste production and its destination, as well as with the production of photovoltaic energy and the treatment and reuse of wastewater. On the other hand, the results indicate that the sustainability actions are not appropriately articulated, with a recent progress signaling towards systematization of actions.
\end{abstract}

Keywords: Sustainability. Environmental management. Educational institutions. IFRN.

\footnotetext{
${ }^{1}$ Doutor em Ciências Sociais pela Universidade Federal de Campina Grande. Professor da Universidade Federal de Campina Grande. irivaldo. cdsa@gmail.com

${ }^{2}$ Mestre em Administração Pública na Universidade Federal de Campina Grande. Professor do Instituto Federal do Rio Grande do Norte. andre.pinheiro@ifrn.edu.br
} 
A organização alvo deste estudo, o Instituto Federal de Educação, Ciência e Tecnologia do Rio Grande do Norte (IFRN), é uma instituição integrante da Rede Federal de Educação Profissional, Científica e Tecnológica. O IFRN e os demais institutos federais se constituem em autarquias, com equiparação às universidades quanto à regulação e à oferta de cursos superiores. No caso do IFRN, ele é estruturado em 21 campi e uma Reitoria, e esta última acaba definindo grande parte das políticas da instituição. Contando com um planejamento sistêmico, norteado por um Plano de Desenvolvimento Institucional (PDI) único, os campi têm autonomia para definir parte das estratégias quanto à oferta dos serviços e à destinação dos recursos a eles descentralizados.

A referida instituição oferece cursos em diversos níveis, abrigando, em suas instalações, atividades de ensino, pesquisa e extensão. Algumas dessas atividades têm potencial de provocar efeitos nocivos ao meio ambiente, sendo necessário contemplar essa dimensão no planejamento institucional, uma vez que os institutos foram criados com o objetivo de promover transformações positivas na sociedade, como "desenvolvimento socioeconômico local, regional e nacional, [...] promover a produção, o desenvolvimento e a transferência de tecnologias sociais, notadamente as voltadas à preservação do meio ambiente" (BRASIL, 2008).

Isso reflete uma tendência recente do poder público em estabelecer práticas sustentáveis em diversas organizações. No ano de 1981 foi publicada a Lei n. 6.938, que instituiu a Política Nacional do Meio Ambiente, contendo princípios como proteção aos ecossistemas, racionalização do uso do solo, subsolo, água e do ar, recuperação de áreas degradadas e educação ambiental, estabelecendo a obrigatoriedade de estudos de impacto ambiental para as obras ou atividades que causem degradação ao meio ambiente (BRASIL, 1981).

A Lei n. 12.349/2010 e o Decreto n. 7.746/2012 modificaram e regulamentaram, respectivamente, o artigo 3ㅇ da Lei n. 8.666/90 (lei que normatiza as licitações e contratos da Administração Pública Federal), a primeira incluindo no texto a observância da "promoção do desenvolvimento nacional sustentável" (BRASIL, 2010), enquanto o Decreto estabelece diretrizes como menor impacto sobre recursos naturais, preferência para produtos de origem local, maior geração de empregos e mão de obra local e institui a Comissão Interministerial de Sustentabilidade na Administração Pública (BRASIL, 2012). Já a Portaria n. 23, de 12 de fevereiro de 2015, do Ministério do Planejamento, Orçamento e Gestão, estabelece boas práticas de gestão e uso de energia elétrica e de água nos órgãos e entidades da Administração Pública Federal e determina que esses órgãos e entidades informem mensalmente os gastos (MINISTÉRIO..., 2015). Um conjunto de normas que tem como finalidade impactar na gestão do serviço público e contribuir para o desenvolvimento sustentável.

Além disso, instituiu um programa de responsabilidade socioambiental, chamado de Agenda Ambiental da Administração Pública (A3P). Sua aplicação é ato discricionário do administrador do órgão ou entidade pública. Trata-se de um programa do Ministério do Meio Ambiente (MMA), em que o órgão presta apoio técnico para instituições interessadas na instalação da Agenda. As instituições, que se credenciam na Rede A3P por meio da assinatura de um Termo de Adesão, passam a desenvolver ações voltadas à sus- 
tentabilidade socioambiental e podem realizar o seu monitoramento mediante indicadores de desempenho (MINISTÉRIO..., 2015a). Segundo o MMA (MINISTÉRIO..., 2015c), até 22 de setembro de 2014 um total de 586 instituições haviam aderido ao programa.

Nesse contexto, surge o seguinte problema de pesquisa: Em que medida o Instituto Federal de Educação, Ciência e Tecnologia do Rio Grande do Norte adota políticas de sustentabilidade? Para responder a essa questão promoveu-se uma avaliação qualitativa e quantitativa, com o auxílio de um sistema de indicadores, de três entre os 21 campi do Instituto. Além da conveniência, como critério utilizou-se o tempo de existência e a estrutura, sendo selecionados campi de porte e tempo de funcionamento diferentes.

A pesquisa teve como objetivo geral analisar a instituição de uma política de sustentabilidade em organização pública, no caso o Instituto Federal de Educação, Ciência e Tecnologia do Rio Grande do Norte. E, para atender a esse objetivo geral, foi necessário o estabelecimento dos seguintes objetivos específicos: verificar o conteúdo da política de sustentabilidade do IFRN; avaliar três campi do IFRN quanto ao desempenho em sustentabilidade e verificar que ações podem ser planejadas para melhoria desse desempenho.

Essa diretiva da sustentabilidade é fruto de um movimento internacional exercido num campo de estudo que poderia ser chamado de ambiental, que vem sendo construído há décadas e fica mais forte com a crescente necessidade de se utilizar de forma racional os recursos naturais.

É importante buscar um mínimo de precisão na definição de "desenvolvimento sustentável", o que parece ser uma tarefa difícil. É possível, entretanto, verificar nos documentos oficiais que dão lastro a essa categoria, como o Relatório Bruntdland, ${ }^{3}$ denominado "Nosso Futuro Comum", que a especificação de "desenvolvimento sustentável" tem relação direta com outras categorias, como humanidade, gerações futuras e qualidade de vida, que não são precisas, o que acaba protegendo (FERNANDES, 2003) a expressão "desenvolvimento sustentável" do enfrentamento de possíveis contradições no campo das relações sociais. O Relatório "Nosso Futuro Comum" define da seguinte maneira "desenvolvimento sustentável":

48. The concept of sustainable development provides a framework for the integration of environment policies and development strategies - the term "development" being used here in its broadest sense. The word is often taken to refer to the processes of economic and social change in the Third World. But the integration of environment and development is required in all countries, rich and poor. The pursuit of sustainable development requires changes in the domestic and international policies of every nation. 49. Sustainable development seeks to meet the needs and aspirations of the present without compromising the ability to meet those of the future. Far from requiring the cessation of economic growth, it recognizes that the problems of poverty and underdevelopment cannot be solved unless we have a new era of growth in which developing countries play a large role and reap large benefits ${ }^{4}$ (Grifos do autor).

3 Apresentado no ano de 1987, pela Comissão Mundial sobre Meio Ambiente e Desenvolvimento.

${ }^{4}$ Disponível em: <http://www.un-documents.net/ocf-01.htm\#Il> 
A definição oficial aproxima inexoravelmente desenvolvimento e sustentabilidade, implicando ambos, ou seja, afirmando que a capacidade de recursos do futuro dependerá do uso no presente. Além disso, prevê a necessidade da integração de políticas ambientais e estratégias de desenvolvimento. Isso significa que se buscarão maneiras "ambientalmente equilibradas" para promover a proteção do meio ambiente. A definição anterior, que influenciou grande parte das nações e projetos de políticas públicas, confirma que a expressão tem um sentido amplo quando utiliza em inglês "broadest sense".

A grande questão acerca da sustentabilidade ou desenvolvimento sustentável está no excesso de significados e definições, os quais são múltiplos e conflituosos, contando com uma pluralidade de atores políticos, bem como multiplicidade e diversidade de metas. Segundo Redclift (2002), algo mais grave está ocorrendo: a sustentabilidade foi se separando do meio ambiente e foi confundida com questões mais amplas da equidade, da governabilidade e da justiça social, o que serviu para transferir a discussão política para diversos lugares. Nesse viés, muitas coisas que são desejáveis são classificadas como sustentáveis, não se tratando de uma expressão exclusivamente ambiental. Ademais, a expressão é vaga, uma vez que se pode verificar o aumento da cooperação de atores opositores potenciais a trabalhar por objetivos comuns. É um termo confuso, talvez fosse interessante "sustentabilidade ecológica", como preferem muitos ambientalistas, sem fazer uma inter-relação com desenvolvimento.

Além disso, o desenvolvimento sustentável utiliza como estratégia de execução a intervenção econômica para corrigir as falhas do mercado, uma solução neoclássica: a internalização dos custos do meio ambiente. No entendimento de Redclift (2002), são esquecidas as implicações políticas da ausência de segurança na definição de "sustentabilidade", ou seja, a ausência de fixidez no seu conceito pode ter repercussão direta na formulação de políticas públicas ambientais, que se ressentem de uma maior sistematização, principalmente no âmbito municipal (SILVA, 2011).

A sustentabilidade é vista como proteção e conservação da natureza em seu conceito mais divulgado, bem como atrelada à melhoria da gestão dos recursos naturais pelos atores envolvidos direta ou indiretamente com processos conhecidos como sustentáveis. As questões relacionadas com a gestão e sustentabilidade permeiam inclusive a lógica estatal, no caso do Brasil, de organização territorial (LEITE; DELGADO, 2001).

Segundo Lenzi (2006), a chave para a compreensão de uma questão ambiental está no entendimento do desenvolvimento sustentável, da modernização ecológica e da sociedade de risco. O pressuposto do desenvolvimento sustentável está muito mais ligado a valores morais do que científicos, preservação do meio ambiente para as próximas gerações; na modernização ecológica o pressuposto é muito mais científico; entretanto, quanto à sociedade de risco, Beck (2010) coloca um verdadeiro véu de desconfiança sobre as promessas de "salvação" pela ciência: como se pode resolver os problemas ambientais com aquilo que ajudou a criá-los? (LENZI, 2006). Na compreensão de Lenzi, também há entendimento multifacetado acerca da sustentabilidade, uma mais retórica, outra mais pragmática e uma terceira com um nível de crítica muito elevado. Dessa forma, o que se pode verificar é a ausência de precisão do termo, senão veja-se no Quadro 1 elaborado a partir da obra de Sachs (2008), que explora o caráter multifacetado da sustentabilidade, posicionando-a em múltiplas dimensões (Quadro 1). 


\section{Quadro 1 - Critérios de Sustentabilidade}

\begin{tabular}{|c|c|}
\hline SOCIAL & $\begin{array}{l}\text { Alcance de um patamar razoável de homogeneidade social; } \\
\text { Distribuição de renda justa; } \\
\text { Emprego pleno e/ou autônomo com qualidade de vida decente; } \\
\text { Igualdade no acesso aos recursos e serviços sociais. }\end{array}$ \\
\hline CULTURAL & $\begin{array}{l}\text { Mudanças no interior da continuidade (equilíbrio entre respeito à tradição e inovação); } \\
\text { Capacidade de autonomia para elaboração de um projeto nacional integrado e endó- } \\
\text { geno; } \\
\text { Autoconfiança combinada com abertura para o mundo. }\end{array}$ \\
\hline ECOLÓGICA & $\begin{array}{l}\text { Preservação do potencial do capital natureza na sua produção de recursos renováveis; } \\
\text { Limitar o uso dos recursos não renováveis. }\end{array}$ \\
\hline AMBIENTAL & Respeitar e realçar a capacidade de autodepuração dos ecossistemas naturais. \\
\hline TERRITORIAL & $\begin{array}{l}\text { Configurações urbanas e rurais balanceadas (eliminação das inclinações urbanas nas } \\
\text { alocações do investimento público); } \\
\text { Melhoria do ambiente urbano; } \\
\text { Superação das disparidades inter-regionais; } \\
\text { Estratégias de desenvolvimento ambientalmente seguras para áreas ecologicamente } \\
\text { frágeis (conservação da biodiversidade pelo ecodesenvolvimento). }\end{array}$ \\
\hline ECONÔMICO & $\begin{array}{l}\text { Desenvolvimento econômico intersetorial equilibrado; } \\
\text { Segurança alimentar; } \\
\text { Capacidade de modernização contínua dos instrumentos de produção; razoável nível } \\
\text { de autonomia na pesquisa científica e tecnológica; } \\
\text { Inserção soberana na economia internacional. }\end{array}$ \\
\hline $\begin{array}{l}\text { POLÍTICA (NA- } \\
\text { CIONAL) }\end{array}$ & $\begin{array}{l}\text { Democracia definida em termos de apropriação universal dos direitos humanos; } \\
\text { Desenvolvimento da capacidade do Estado para estabelecer o projeto nacional, em } \\
\text { parceria com todos os empreendedores; } \\
\text { Um nível razoável de coesão social. }\end{array}$ \\
\hline $\begin{array}{l}\text { POLÍTICA (IN- } \\
\text { TERNACIONAL) }\end{array}$ & $\begin{array}{l}\text { Eficácia do sistema de prevenção de guerras da ONU, na garantia da paz e na coopera- } \\
\text { ção internacional; } \\
\text { Um pacote Norte-Sul do codesenvolvimento, baseado no princípio da igualdade (re- } \\
\text { gras do jogo e compartilhamento da responsabilidade de favorecimento do parceiro } \\
\text { mais fraco); } \\
\text { Controle institucional efetivo do sistema internacional financeiro e de negócios; } \\
\text { Controle institucional efetivo da aplicação do princípio da precaução na gestão do } \\
\text { meio ambiente e dos recursos naturais; prevenção das mudanças globais negativas; } \\
\text { proteção da diversidade biológica (e cultural) e gestão do patrimônio global, como } \\
\text { herança comum da humanidade; } \\
\text { Sistema efetivo de cooperação científica e tecnológica internacional e eliminação par- } \\
\text { cial do caráter de commodity da ciência e tecnologia, também como propriedade da } \\
\text { herança comum da humanidade. }\end{array}$ \\
\hline
\end{tabular}

Fonte: Elaboração própria a partir de critérios postos na obra Sachs (2008).

Assim sendo, pode-se agrupar os sentidos de desenvolvimento sustentável em algumas categorias de compreensão, mais precisamente em duas gerais, mas possível de encontrar outras:

Desenvolvimento sustentável que possui um sentido caótico, ou seja, não há possibilidade da convivência entre proteção e conservação ambiental e desenvolvimento econômico; se a matriz ideológico-política não sofrer mudanças bruscas, do contrário o que se tem são meras palavras, enfim, apenas intenções - aí tem-se uma compreensão política do fenômeno, não apenas técnica, meramente contida em explicações matemáticas ou econômicas acerca da conservação da natureza. 


\begin{abstract}
Um sentido que ameniza a expressão, ou seja, desenvolvimento sustentável é bom, necessário para que não se interrompa o ciclo de crescimento econômico, precisa-se saber conviver com a nova realidade mundial, ou seja, uma realidade de escassez, mas que pode ser convertida numa oportunidade de mudança. Isso pode ser respondido a partir de uma melhor gestão dos recursos naturais, instaurando essa lógica nos mais diversos setores, inclusive nos projetos estatais e até no comportamento individual das pessoas.
\end{abstract}

Os sentidos da sustentabilidade têm sido tensionados claramente por duas interpretações dessa realidade que se poderia chamar de: o ecologismo científico e o ecologismo militante. A primeira baseada numa perspectiva racional que legitima seu discurso por meio das evidências científicas; a segunda busca legitimidade na discussão política da ecologia, questionando os processos e dinâmicas que estão por trás, como afirma Gaudiano (2007), que o tema ambiental sugere uma amplitude considerável de posições discursivas, dando conta de interesses diversos acerca da gestão ambiental e das políticas públicas. Cada grupo defensor de um ou vários sentidos de sustentabilidade procura hegemonizar sua perspectiva acerca do meio ambiente.

Dessa forma, pode-se afirmar que o debate público sobre a questão ambiental é informado segundo perspectivas que vão de um fundamentalismo ambiental a uma busca pela fusão entre o desenvolvimento e a dimensão ambiental (sustentabilidade). Segundo Fernandez (2006), meio ambiente e desenvolvimento devem ser compatíveis, e isso seria o cerne de uma política ambiental. Analisando a política do México, mas trazendo essa perspectiva às ações do governo brasileiro, parece que o núcleo da política local é justamente esse.

A definição de um sentido a ser seguido recairá sobre a agenda pública do país, afetando de maneira direta o meio ambiente e os recursos naturais, principalmente quando se tem como intenções globais a expansão dos mercados, a transformação do Estado e instituições políticas e o surgimento de novos movimentos sociais e políticos.

No que se refere especificamente a ferramentas de gestão ambiental, essas ganham força há bastante tempo nas organizações privadas e, mais recentemente, nas organizações públicas, principalmente a substancial pressão que o meio ambiente sofre a cada dia com o aumento do consumo dos recursos naturais, como água e produtos das florestas, revelando-se isso uma tônica global, dado que o papel da governança pública tem sido instalar mecanismos que possam monitorar e ajudar em soluções sustentáveis no cotidiano das organizações (LOIZIDOU; OGLANIS, 2017). É preciso impactar positivamente nas cidades em que essas estruturas públicas foram montadas, ser exemplo, participar de um planejamento maior dentro da cidade, e para isso é necessário fazer uma espécie de "tarefa de casa", monitorando e diagnosticando os pontos de pressão ao meio ambiente que os IFs possuem por exemplo (DIZDAROGLU; YIGITCANLAR, 2015).

\title{
SUSTENTABILIDADE NAS INSTITUIÇÕES DE ENSINO
}

Apesar da grande responsabilização imputada às empresas, a sustentabilidade não deve estar restrita ao setor produtivo com fins lucrativos, mas a todos os que fazem parte da sociedade (FURTADO, 2005). Seguramente as Instituições de Ensino Superior (IES) podem desempenhar papéis importantes na promoção da sustentabilidade, tanto no debate sobre o tema, conscientização e apontamento de soluções para os proble- 
mas, quanto na adoção de práticas que promovam a educação pelo exemplo. Segundo Kruger et al. (2013), elas têm como diferencial a atuação em ensino, pesquisa e extensão visando ao desenvolvimento sustentável do meio em que estão inseridas, respeitando as demandas sociais e ambientais, independentemente se são públicas ou privadas.

Tauchen e Brandli (2006) apontam para um papel adicional das IES: as suas práticas de sustentabilidade. Segundo os autores, os estabelecimentos comparam-se a pequenas cidades, nas quais há diversas atividades e uma infraestrutura complexa, ocorrendo tanto a geração de resíduos e efluentes quanto um grande consumo de recursos. Vaz et al. (2010) concordam que as IES executam atividades que podem gerar impactos sobre o seu ambiente. Segundo eles, essas instituições dispõem de laboratórios que geram diversos tipos de resíduos líquidos e sólidos, com potencial poluidor. Nesse sentido, "devem combater os impactos ambientais gerados para servirem de exemplo no cumprimento da legislação, saindo do campo teórico para a prática" (TAUCHEN; BRANDILI, 2006, p. 505).

Analogamente, os Institutos Federais de Educação, Ciência e Tecnologia possuem responsabilidade na preservação e controle dos efeitos provocados por suas atividades ao meio ambiente. Daí deriva a importância da adoção de medidas que promovam a sistematização das ações necessárias. Os Sistemas de Gestão Ambiental (SGA) são, de acordo com Souza e Pfitscher (2013, p. 10), "instrumentos de gestão que podem auxiliar nas tomadas de decisão das instituições públicas e privadas".

A gestão ambiental no âmbito dos Institutos Federais, porém, apresenta deficiências, como evidencia o estudo realizado por Borges et al. (2013). Eles avaliaram 82 campi de Institutos Federais de Educação, Ciência e Tecnologia quanto ao seu desempenho ambiental, não encontrando entre esses nenhum campus com desempenho médio, bom ou muito bom, mas apenas desempenhos entre fraco e muito fraco, o que revelou uma baixa preocupação com o meio ambiente por parte dessas instituições. Apesar desse resultado, algumas dessas instituições estão buscando a instalação de um sistema de gestão ambiental. Aderiram à Agenda Ambiental da Administração Pública 14 instituições integrantes da Rede Federal de Educação Profissional, Científica e Tecnológica, de acordo com o Ministério do Meio Ambiente (2015c), entretanto certamente será importante para a gestão ambiental no serviço público e, no caso em análise, nos Institutos Federais (IFs), promover análises a partir da adoção de políticas baseadas em dados e formulação de indicadores específicos acerca, por exemplo, do uso de água, a geração de resíduos sólidos, entre outras variáveis relevantes para o desenvolvimento sustentável (PACHANA et al., 2015). Outrossim, é importante analisar os dados disponíveis e refletir acerca de modelos de intervenção nas organizações para a gestão ambiental das externalidades produzidas (SUSHIL et al., 2017).

\section{ESTADO DA ARTE NA APLICAÇÃO DE INDICADORES EM GESTÃO AMBIENTAL}

Além do estudo de Borges et al. (2013), outros foram realizados tendo como objeto o nível de sustentabilidade nas IES. Tauchen e Brandli (2006) fizeram um levantamento de universidades com ações sustentáveis, pesquisando ao todo 42 IES, visando à construção de um modelo de sistema de gestão ambiental para instalação nessas orga- 
nizações. Como resultado, encontraram entre as principais ações o controle do consumo e o reuso da água, gestão de resíduos e reciclagem, educação ambiental, auditoria ambiental e diagnóstico dos impactos diretos.

Teixeira e Azevedo (2013) analisaram as implicações da Instrução Normativa n. 1/2010 da Secretaria de Logística e Tecnologia da Informação do Ministério do Planejamento, Orçamento e Gestão (MPOG), que dispõe sobre os critérios de sustentabilidade ambiental na aquisição de bens, serviços ou obras pela Administração Pública Federal. Verificaram: a) um aumento dos custos, num primeiro momento, na compra de materiais, obras e serviços dentro dos padrões ambientais, na administração pública; b) resistência dos gestores em fazer aquisições sustentáveis pelo receio quanto às justificativas aos órgãos de controle, tendo em vista a imprecisão do princípio da "promoção do desenvolvimento nacional sustentável" e c) uma sobreposição das ações dos diversos órgãos de controle, tornando complexo o trabalho dos gestores (TEIXEIRA; AZEVEDO, 2013).

Warken, Henn e Rosa (2014) avaliaram o nível de sustentabilidade ambiental de um campus da Universidade Federal Fronteira Sul. Para isso, utilizam um sistema de indicadores, o Modelo de Avaliação de Sustentabilidade Socioambiental (Mass), elaborado por Freitas (2013). Esse modelo consiste em 12 eixos temáticos, divididos em grupos: compras, infraestrutura, administração, ensino, pesquisa e extensão. Cada eixo recebeu uma classificação de acordo com o índice calculado pelas respostas ao questionário, enquadrando-se como adequado, regular ou deficitário. A grande variação entre os resultados de cada eixo identificou os pontos fortes e fracos da instituição quanto à sustentabilidade.

A pesquisa de Warken e Klann (2014) foi realizada na mesma instituição, também com a utilização do Mass, mas eliminando-se dois dos 12 eixos temáticos. O objetivo foi analisar as forças isomórficas influenciando as práticas de sustentabilidade ambiental adotadas pela instituição e, por esse motivo, entre as opções de respostas foram incluídas: inovação por mudanças tecnológicas, inovação por legislação e inovação por força de mercado. Concluíram que, a exemplo do constatado por outros estudos, as práticas da universidade são também influenciadas de maneira mais decisiva pelo isomorfismo coercitivo e normativo, ou seja, pela legislação e profissionalização, e um pouco menos pelo isomorfismo mimético.

Luiz et al. (2014) investigaram a existência de auditoria ambiental em uma instituição federal de educação por meio de uma análise qualitativa do conteúdo dos planos anuais de auditoria interna e dos seus relatórios anuais, além dos dados dos relatórios de gestão referentes às licitações sustentáveis. Com base na legislação vigente, os autores propõem um plano de auditoria ambiental. Entre as conclusões do estudo está a concepção de que devem ser priorizados dois tópicos nas instituições de ensino: as licitações sustentáveis e as atividades de ensino, pesquisa e extensão.

O estudo de Rocha, Pfitscher e Carvalho (2015) utilizou o Sistema Contábil Gerencial Ambiental (Sicogea) para calcular o nível de sustentabilidade de uma Instituição de Ensino Superior de Santa Catarina. Para isso fez uso de questionário aplicado aos responsáveis por três setores da instituição. O resultado global foi considerado fraco e ensejou a proposição de um plano resumido de gestão ambiental com estrutura $5 \mathrm{~W} 2 \mathrm{H}$ (em português: o quê, quando, onde, por que, quem, como, quanto custa). 
A avaliação de sustentabilidade, por meio de sistemas de indicadores é recorrente na produção acerca do tema, o que argumenta em favor da utilização de sistemas de indicadores de sustentabilidade, que é percebida tanto pela academia quanto pelo Estado, com o uso da A3P. Nesse sentido, a fim de realizar um diagnóstico da instituição quanto ao seu desempenho ambiental e para relacioná-lo a sua política e ações a ela vinculada, mostra-se pertinente a adoção de um sistema de indicadores de sustentabilidade. $\mathrm{O}$ uso de indicadores ambientais constitui-se em uma ferramenta essencial em gestão e avaliação ambiental (BORGES et al., 2013). Por meio deles será possível evidenciar as áreas que mais contribuem para a sustentabilidade e as que necessitam ajustes e correções.

\section{DESCRIÇÃO DOS CAMINHOS METODOLÓGICOS}

Esta pesquisa consistiu em estudo empírico-descritivo, em que se avaliou a sustentabilidade do IFRN por meio da mensuração do desempenho de três dos 21 campi da instituição. Como recorte temporal a pesquisa utilizou dados relativos aos anos de 2015 e 2016, com vistas a verificar a situação atual da organização.

Foi realizado o levantamento das ações de sustentabilidade promovidas na instituição, seguindo-se para a mensuração do desempenho em sustentabilidade de três campi: o Campus Natal-Central, unidade mais antiga e de maior infraestrutura, estrutura administrativa e número de alunos atendidos; o Campus Currais Novos, fruto da primeira fase da expansão da instituição, criado em 2006, e o Campus Avançado de Parelhas, uma das duas unidades mais novas. Dessa forma, buscou-se contemplar os diversos estágios de desenvolvimento dos campi do IFRN.

Foram utilizados os indicadores propostos na fase de investigação e mensuração (primeira fase da terceira etapa) do Sicogea - 2a Geração, elaborado por meio da contribuição de Nunes (2010) à metodologia de Pfitscher (2004). A escolha desse sistema deveu-se a sua adequação ao contexto de organização pública e pela possibilidade de geração de índices que permitem a identificação de forças e fragilidades em relação à sustentabilidade na instituição.

Como fonte para coleta de dados foram analisados relatórios de sistemas de informação utilizados pela instituição, relatórios de gestão do IFRN, outras informações divulgadas oficialmente pela instituição (dados secundários), além da aplicação de questionário cujo preenchimento foi solicitado à administração dos campi. Entre as 123 perguntas, a de número 45 foi descartada quando da definição das pontuações máximas (procedimento descrito a seguir) e a de número 103 foi considerada não aplicável, no momento da execução, pelos respondentes dos três campi, em consequência disso sendo desconsiderada.

Para definição da participação de cada indicador no cálculo dos índices, Nunes (2010) recomenda o estabelecimento de pontuações diferenciadas para cada indicador, quando o próprio pesquisador seria responsável pela atribuição de maior peso a questões que julgue de maior relevância. Optou-se, porém, por consultar a opinião dos atores institucionais de um campus de instituto federal. Foram aplicados questionários estruturados com 123 perguntas de múltipla escolha, encaminhados a 18 servidores, retornando respondidos 13 desses documentos. 
Indagou-se qual a importância dos indicadores a um público composto por servidores do instituto federal, solicitando-se que respondessem sobre o que se relacionava com seu perfil profissional e área de atuação. Foram propostos, nessa etapa, graus de importância por indicador, considerando-se os seguintes valores no cálculo da pontuação máxima do item: não se aplica - 0 ponto, pouco importante - 1 ponto, importante - 2 pontos, muito importante -3 pontos e prefiro não opinar - Não contabilizado. Para cada item foi calculada a mediana das respostas dos atores institucionais. Itens cuja mediana fosse inferior a 1 seriam descartados.

Posteriormente, no mês de abril de 2016, foi realizada a coleta dos dados dos três campi selecionados, mediante a aplicação da lista de verificação, solicitando-se à administração dos campi o seu preenchimento. A lista de verificação utilizada contém 123 perguntas que, a partir da contribuição do autor ao método anterior, respondidas pela atribuição de uma avaliação de 0 a 5 ou não se aplica. Essa última, segundo Nunes (2010), possibilita o descarte do questionamento, de forma que não prejudique o cálculo de sustentabilidade.

Quanto ao tratamento dos dados para a definição da pontuação obtida na avaliação de cada indicador, calculou-se o percentual da pontuação máxima do item, correspondente à resposta dada em escala de 0 a 5 . Ou seja, após a aplicação da lista de verificação, de acordo com Nunes (2010), deve-se atribuir a cada indicador o valor referente a suas pontuações máximas, multiplicado pelo percentual referente à resposta, conforme correspondência exposta na Tabela 1.

Tabela 1 - Atribuição de pontuação por item

\begin{tabular}{c|c}
\hline Resposta & Pontos atribuídos \\
\hline 0 & $0 \%$ do total de pontos do item \\
\hline 1 & $20 \%$ do total de pontos do item \\
\hline 2 & $40 \%$ do total de pontos do item \\
\hline 3 & $60 \%$ do total de pontos do item \\
\hline 4 & $80 \%$ do total de pontos do item \\
\hline 5 & $100 \%$ do total de pontos do item \\
\hline
\end{tabular}

Fonte: NUNES, 2010.

A contribuição do subgrupo na composição do índice de sustentabilidade é calculada pela Fórmula 1, adaptada de Nunes (2010). As parcelas de contribuição máximas dos subgrupos são de 100/7 (aproximadamente 14,3\%).

$$
\mathrm{Cs}=[(\mathrm{Pa} / \mathrm{Pp}) \cdot 100 / 7] / 100
$$

Onde $\mathrm{Cs}=$ Percentual de contribuição do subgrupo, $\mathrm{Pa}=$ Pontos alcançados e $\mathrm{Pp}=$ Pontos possíveis do subgrupo. Para a verificação do desempenho dos campi, bem como o geral, foram calculados os percentuais de contribuição em cada subgrupo, por meio da Fórmula 2. Já o índice geral de sustentabilidade do campus foi calculado pelo somatório dos percentuais de contribuição dos subgrupos. Da mesma forma, para o cálculo do índice de sustentabilidade médio, ou seja, do conjunto dos campi avaliados, utilizou-se a Fórmula 2, usando dessa vez as contribuições médias dos subgrupos.

$$
\mathrm{Cms}=(\text { Cpaas }+\mathrm{Ccn}+\mathrm{Ccnat}) / 3
$$

Onde: Cpaas $=\%$ contribuição do subgrupo obtido pelo Campus Avançado de Parelhas; $\mathrm{Ccn}=\%$ contribuição do subgrupo obtido pelo Campus Currais Novos e Ccnat $=\%$ contribuição do subgrupo obtido pelo Campus Natal-Central. 


\section{RESULTADOS E DISCUSSÃO}

\section{Ações Desenvolvidas Como Pressuposto da Estruturação da Gestão Ambiental}

Entre as ações desenvolvidas na organização estudada tem-se a formalização da política de sustentabilidade, por meio da construção de alguns documentos como a Política Socioambiental do Instituto Federal de Educação, Ciência e Tecnologia do Rio Grande do Norte, baseado nas Agendas 21 Global e Brasileira (INSTITUTO..., 2015a) e o Plano de Logística Sustentável (PLS), que pretende "aprimorar e sistematizar as boas práticas de sustentabilidade já em andamento pelo IFRN através do projeto Campus Verde e fornecer diretrizes para novas ações" (INSTITUTO..., 2013, p. 6). Sabe-se, no entanto, que é preciso muito mais que documentos para a eficácia de uma determinada política numa organização. Como alertam Camargo, Liboni e Oliveira (2015), o envolvimento dos que constituem o órgão é fundamental para que uma ação da envergadura da política de sustentabilidade funcione numa dada organização. A estruturação de uma organização em torno de uma política de desenvolvimento sustentável exaltando ferramentas de gestão ambiental envolve atores internos e externos, públicos e privados, e pode ser encarada como uma inovação no serviço público, diante da sua baixa aplicação no ambiente governamental (PAULINO; CRUZ, 2013).

Um dos projetos importantes é o que resultou do trabalho da equipe do Projeto Campus Verde, que objetivou a instalação do Sistema de Gestão Ambiental (SGA) na instituição, prevendo a formação de comissão sistêmica e comissões locais, responsáveis por estabelecer e supervisionar as ações de sustentabilidade propostas em cada campus. Dos três campi selecionados, apenas o Campus Natal-central e o Campus Currais Novos possuíam essa comissão, enquanto o Campus Avançado de Parelhas ainda não havia formado sua comissão. Esse é um envolvimento extremamente relevante para impulsionar a trajetória dessa política internamente na organização; os atores precisam se convencer dos pressupostos dos princípios dos projetos de sustentabilidade (CAMARGO; LIBONI; OLIVEIRA, 2015). É preciso levar em conta, porém, o estudo de Borella, Barcellos e Bertolazzi (2011), fazendo-se necessário compreender primeiramente qual tem sido o sentido empregado na organização aos elementos "meio ambiente" e "sustentabilidade" e, ao que parece, essa organização estudada não fez nenhum levantamento nesse aspecto, o que pode redundar em insucessos no avançar do estabelecimento de ações. O estudo prévio pode diminuir a probabilidade de fracassos.

No âmbito da responsabilidade social, o IFRN possui o Núcleo de Estudos Afro-Brasileiros e Indígenas (Neabi), que de acordo com seu regimento "é um grupo responsável por fomentar ações de natureza sistêmica, no âmbito do ensino, pesquisa e extensão, que promovam o cumprimento efetivo das leis n. 10.639/2003 e 11.645/2008 e os demais instrumentos legais correlatos" (INSTITUTO..., 2011). Além dele, dispõe-se dos Núcleos de Apoio às Pessoas com Necessidades Educacionais Específicas (Napne), que objetiva a inclusão e oferecer as condições necessárias a esse público para seu ingresso e permanência na instituição e do Programa Mulheres Mil, que oferta educação profissional a mulheres de baixa renda, com o intuito de promover uma inclusão social, autonomia e a melhoria na qualidade de vida delas e de suas comunidades (MINISTÉ- 
RIO..., 2008). Essa dimensão social, segundo alguns teóricos como Sachs (2008), tem relação com um visão mais ampliada de desenvolvimento sustentável, sustentabilidade e meio ambiente como abordado supra. Isso amplia a imprecisão do conceito de desenvolvimento sustentável, porém é uma dimensão que não pode ser desconsiderada, uma vez que as relações sociais estão incluídas nesse contexto.

Talvez por falha na formação dos administradores, entretanto, ou porque na gestão pública há poucos profissionais com formação em Administração, a "responsabilidade social" torna-se um tema menos importante no desenvolvimento das organizações. Segundo pesquisas no setor privado (PIRES et al., 2017), as empresas buscam um profissional que possa desenvolver projetos no tripé "responsabilidade econômica, social e ambiental", inclusive valorizando aquele que tenha essas características. Certamente isso seria de difícil efetivação, mas não impossível, no ambiente organizacional público, cujas regras, geralmente, são mais rígidas, e o princípio da legalidade impera.

Outra ação sistêmica nessa área é a instalação nos campi, desde o ano de 2015, das Comissões Internas de Saúde do Servidor Público (Cissp), equivalentes às CIPAs (Comissão Interna de Prevenção de Acidentes) do setor privado. Elas têm como atribuição propor ações de promoção à humanização do trabalho, melhoria das condições e de prevenção de acidentes e de doenças relacionadas a este e contribuir nas questões ligadas ao meio ambiente (INSTITUTO..., 2015b). Mais uma atuação que pode promover o envolvimento da equipe e cuja dimensão humana se adapta a uma dimensão mais ampla de sustentabilidade, só havendo de fato um desenvolvimento sustentável na medida em que se há respeito à dimensão humana igualmente, isso pode ser exercitado no setor público como forma de gestão ambiental (MINAYO-GOMEZ; BARATA; KLIGERMAN, 2007). Os temas saúde e desenvolvimento sustentável, no âmbito do serviço público, no entanto, são pouco abordados, sendo mais frequentes no setor privado (FREIRE, 2008; CASTRO; MONTEIRO, 2015; CARVALHO et al., 2017). Há ainda o Programa de Promoção de Saúde de Qualidade de Vida do Servidor, instituído por meio de um conjunto de projetos anualmente planejados e postos em prática por comissões locais. Esta é uma preocupação característica com o meio ambiente do trabalhador no setor público.

Uma outra ação concreta em torno de uma política de desenvolvimento sustentável na instituição foi o investimento realizado recentemente em produção de energia solar fotovoltaica, estando à época do estudo oito usinas em funcionamento; a instituição é a primeira do Estado a contar com o novo sistema (INSTITUTO..., 2016). É um investimento que, no médio e longo prazos repercutirá em economia de despesa para a instituição, além do que, a relevância e a urgência para a adoção de energia de matriz limpa e renovável tornou-se um imperativo inexorável (MENDES, 2010; SOUZA et al., 2013; GOMES; FRANCO; CALADO, 2014), devendo a gestão das organizações públicas adotarem os procedimentos necessários para a adequação aos novos tempos, embora seja sabido que essa transformação é mais lenta no setor público.

Outra dimensão que não pode ser relegada a segundo plano no planejamento estratégico de uma organização pública, no caso em tela o IFRN, é aquela atinente às ações no âmbito da educação ambiental, as quais são realizadas por meio de eventos anuais denominados "Semana do Meio Ambiente", em que se desenvolvem atividades expositivas e discussões acerca do tema. Há também a realização de projetos de extensão relacionados à preservação do meio ambiente e à responsabilidade social. Esse 
processo educativo, entretanto, precisa ser continuado e monitorado, sendo propício para a instituição da educação ambiental como parte da estrutura organizacional. Como afirmam Loureiro e Costa (2017), o processo de educação ambiental é essencialmente interdisciplinar e complexo, portanto pensa-se que numa organização isso precisa ser trabalhado de forma multidisciplinar e, em se tratando de uma instituição educacional, talvez isso seja possível mais facilmente com a própria equipe de profissionais que já existe, sendo necessário partir de um reconhecimento dos atores acerca da necessidade de se pôr em prática ações voltadas à educação ambiental. Acredita-se que os processos de intervenção numa organização pública devem ocorrer na linha do que Ratto, Henning e Andreola (2017) afirmam, e segundo eles é urgente a institucionalização de uma ética ambiental planetária, não havendo mais o que esperar para sua real execução, o que significa que as organizações públicas precisam ser o exemplo, o paradigma mínimo para a sociedade.

O Campus Avançado de Parelhas, por exemplo, desenvolve algumas ações de sustentabilidade desde o início de suas atividades, em 2015. Localizado em região de clima semiárido, o Campus Avançado realiza a captação de águas por poços tubulares, além do estabelecimento de um sistema de captação de águas pluviais. A fachada do prédio conta com a proteção contra a radiação solar, o que contribui para a redução da necessidade de climatização dos ambientes internos. Além disso, está em andamento a arborização de seu terreno. Quanto à gestão de resíduos, promove, mediante ação do Projeto Campus Verde, a adoção de copos individuais em substituição aos descartáveis, reduzindo o seu consumo. Procede coleta seletiva dos resíduos sólidos do Campus, destinando o material reciclável à associação local de catadores. Promove, ainda, o tratamento dos efluentes antes do descarte no ambiente.

Pinto e Mondelli (2017), em recente pesquisa, demonstram que é possível o manejo eficiente de resíduos sólidos em espaços que reúnem diversas pessoas, porém, no que se refere à natureza do espaço, sendo público, deveria existir um engajamento das pessoas, dos atores que constituem esse espaço. Uma das dimensões é contextualizar os projetos e programa da gestão ambiental com o local. Segundo Almeida, Scatena e Luz (2017), isso é fundamental para o êxito de qualquer política, verificando que ferramentas e que soluções são adequadas, em se tratando de uma região semiárida, por exemplo, a questão hídrica torna-se prioritária, devendo fazer parte de uma agenda da organização.

Na dimensão social, o Campus atua no trabalho de educação para a cidadania por meio do Projeto de Extensão "Juventude e Direitos Humanos", mediante o qual desenvolve debates com a comunidade sobre temas como a violência urbana, o sistema penitenciário brasileiro, a violência policial, cidadania e redução da maioridade penal. Essa dimensão social, como já enfatizado supra, faz parte de uma visão mais complexa do desenvolvimento sustentável, que não se restringe aos ecossistemas de fauna e flora, mas expande-se para o bem-estar da comunidade, da sociedade, sendo necessário uma interação com o entorno da organização pública, IF e comunidade.

O Campus Currais Novos também se localiza em região de clima semiárido e adota algumas medidas para a redução do consumo da água fornecida pela companhia de água do Estado e garantia de funcionamento dos serviços em grandes períodos de estiagem. 
As pias são equipadas com torneiras automáticas para que se evite desperdícios. Possui sistema de captação de água das chuvas, abastecendo uma série de cisternas, com capacidade para 600.000 litros. Além disso, há um sistema para a utilização de água de poço, em que o líquido, encontrado impróprio para o consumo, passa por processo de dessalinização. Nele, $50 \%$ da água é transformada em água própria para o consumo humano e os $50 \%$ restantes são destinados a tanques de criação de tilápias (utilizadas em ensino e pesquisa e na alimentação escolar). Quanto à destinação do esgoto, há uma estação de tratamento de efluentes, antes da descarga no ambiente. Adicionalmente, as águas servidas pelo uso das pias e chuveiros são utilizadas na irrigação de pomar mantido pela instituição, do qual se colhe frutas para fins de ensino e pesquisa, assim como para o consumo dos alunos no programa de alimentação escolar.

A unidade tem adotado algumas ações previstas no Projeto Campus Verde, como a impressão de documentos em frente e verso, a redução do uso de copos plásticos descartáveis a partir da utilização de canecas e squeezes e o uso racional dos condicionadores de ar. Além dessas medidas, faz a coleta de pilhas e baterias, encaminhando à Reitoria para destinação correta, e de óleo de cozinha utilizado em fritura na cantina e refeitório e o eventualmente levado por alunos e servidores, resultante do consumo doméstico. Esse óleo é reciclado em projeto do IFRN, produzindo sabão em barra. Há um ciclo interno que promove atividades que servem de laboratório para os estudantes e ao mesmo tempo ocorre uma interação com professores e técnicos.

O Campus Natal-Central, mais antigo e de maior porte, possui entre suas ofertas educacionais o Curso Técnico em Controle Ambiental, o Curso Superior de Tecnologia em Gestão Ambiental e alguns cursos de Pós-Graduação: o Curso de Pós-Graduação Lato Sensu em Gestão Ambiental; o Curso de Pós-Graduação Lato Sensu em Licenciamento Ambiental On Shore; e o Curso de Mestrado Profissional em Uso Sustentável de Recursos Naturais. Com isso, essa unidade tem larga presença dos temas relacionados à preservação do meio ambiente e à responsabilidade social entre os objetos dos projetos de pesquisa e extensão.

O Campus atua fornecendo apoio técnico-científico no Programa Água Azul, juntamente com as Universidades Estadual e Federal do Rio Grande do Norte. O Programa é realizado pelo Instituto de Desenvolvimento Sustentável e Meio Ambiente do Estado do Rio Grande do Norte (Idema), pelo Instituto de Gestão das Águas do Estado do Rio Grande do Norte (Igarn) e pela Empresa de Pesquisa Agropecuária do Estado do Rio Grande do Norte (Emparn). De acordo com a gestão do Programa (PROGRAMA ÁGUA AZUL, 2016):

O Programa tem por objetivos realizar o monitoramento sistemático da qualidade das águas dos principais corpos d'água interiores Norte-rio-grandenses, bem como das águas subterrâneas, verificar as condições de balneabilidade de praias do Estado, além de promover uma investigação passivo ambiental, decorrente da contaminação, por derivados de petróleo, do aquífero na Cidade de Natal.

O Programa mantém um site eletrônico no qual divulga dados sobre a balneabilidade das praias, informando aos cidadãos que praias são próprias ou impróprias para banho. Apoia ainda projetos sociais como o Projeto Fraldinha - projeto social que promove acesso à prática de esporte para crianças e adolescentes em situação de vulnera- 
bilidade - e o escotismo, abrigando nas suas dependências a sede do Grupo Escoteiro do Mar Artífices Náuticos. O Campus realiza gestão sustentável dos resíduos sólidos, baseada em: redução do consumo, coleta seletiva dos materiais descartados; destinação dos materiais reciclados a uma cooperativa de reciclagem; compostagem e vermicompostagem dos materiais orgânicos; produção de mudas utilizando o adubo orgânico resultante dos processos de compostagem.

\section{Aplicação do Sicogea 2a Geração: Sistema Contábil Gerencial Ambiental}

O uso de indicadores numa organização pública propicia a transparência em sua conduta perante o usuário e a sociedade como um todo, retratando pontos frágeis e fortes. Pesquisas apontam, o que já foi percebido há tempos pela iniciativa privada (FERREIRA; GEROLAMO, 2016), que a introdução de ações voltadas à gestão ambiental melhora a "reputação" da organização, interna e externamente, os usuários, certamente, terão sua satisfação aumentada por estarem, de alguma forma, contribuindo para a conservação dos recursos naturais. Realizada aplicação da lista de verificação nos três campi selecionados, no critério "Processos de Prestação de Serviço", os resultados demonstraram maior utilização de campanhas de uso racional dos recursos pelo Campus Natal-Central. Já os indicadores que envolvem certificação de processos e incentivos a iniciativas internas para resolução de demandas ambientais não foram pontuados por nenhum dos campi. O mesmo foi observado nos indicadores sobre capacitação de fornecedores, metas no gerenciamento dos fornecedores e a conduta destes quanto à responsabilidade socioambiental. Isso será base para a avaliação da política de desenvolvimento sustentável interna.

Nos resultados do Grupo "Recursos Humanos", as maiores forças referem-se a aspectos invariáveis, estando vinculados à legislação ou às normas internas sistêmicas. Mais uma vez ficou evidenciada a ausência do monitoramento de metas, nesse caso, sobre a eficiência na gestão de pessoal. Uma série de indicadores revelou a ausência de métodos definidos para os processos internos em gestão do capital intelectual, por exemplo, incentivo à participação voluntária em projetos sociais, feedback, coaching, investimento e desempenho na área ambiental.

Alguns resultados do critério Responsabilidade Socioambiental (grupo Marketing) demonstraram fraco desempenho na sistematização da interação com a comunidade, controle da satisfação dos usuários e na comunicação das ações de sustentabilidade. Os resultados do Grupo Finanças, por sua vez, indicaram expressivamente a inexistência de passivos ambientais, como multas e indenizações, mas um baixo desempenho foi observado no indicador que trata da utilização de parâmetros econômicos sobre a sustentabilidade econômica.

Os percentuais de cada indicador, multiplicados por sua pontuação máxima, geraram o valor em pontos de cada indicador. Os somatórios desses valores, em cada critério, originaram os resultados desses subgrupos, que seguem apresentados na Tabela 2. Ela expressa o percentual aproximado de pontos obtidos em relação à pontuação máxima dos critérios, além da média calculada. 
Tabela 2 - Percentual alcançado em cada subgrupo por campus

\begin{tabular}{c|c|c|c|c}
\hline \multicolumn{1}{c|}{ CAMPI } & PAAS & CN & CNAT & Média \\
\hline PUBGRUPOS & $41 \%$ & $28 \%$ & $69 \%$ & $46 \%$ \\
\hline Processos de prestação de serviço & $38 \%$ & $45 \%$ & $67 \%$ & $50 \%$ \\
\hline Manutenção & $21 \%$ & $37 \%$ & $42 \%$ & $34 \%$ \\
\hline Equipe de colaboradores & $54 \%$ & $53 \%$ & $65 \%$ & $57 \%$ \\
\hline Gestão da instituição & $46 \%$ & $40 \%$ & $73 \%$ & $52 \%$ \\
\hline Responsabilidade socioambiental & $44 \%$ & $40 \%$ & $64 \%$ & $48 \%$ \\
\hline
\end{tabular}

Fonte: Elaborada pelos autores conforme dados da pesquisa.

Na média dos campi, o único subgrupo com desempenho considerado fraco (de $21 \%$ a 40\%) foi o de "Manutenção", refletindo baixos desempenhos nos três campi. Nesse critério, ficou evidenciado que não há preocupação por parte da instituição quanto à gestão ambiental no âmbito das empresas de manutenção, apenas a escolha de uso de produtos ambientalmente corretos por parte delas nas suas atividades. Outra fragilidade encontrada nesse critério foi quanto ao monitoramento dos níveis de poluição sonora, luminosidade, poluição do ar e ergonomia de equipamentos no ambiente interno, importantes na prevenção de doenças relacionadas ao trabalho.

Por outro lado, como destaque positivo do conjunto dos campi estudados, aparece o critério "Contabilidade Gerencial e Auditoria Ambiental", em que o resultado médio está classificado como bom. Nele, os campi tiveram boa avaliação, com a ajuda de fatores como a existência de bens em uso no processo de proteção, controle, preservação e recuperação ambiental, a inexistência de multas e indenizações ambientais, e pela avaliação de que seu orçamento é elaborado e gerenciado, em grande parte, considerando as estratégias e as necessidades operacionais da instituição.

Individualmente, o Campus Avançado de Parelhas, além do subgrupo "Manutenção", obteve desempenho fraco em "Fornecedores". A ausência de mecanismos de condições de qualidade na contratação, da exigência de certificação ambiental do fornecedor e de uma priorização aos que tenham programas na área ambiental foram itens que prejudicaram esse desempenho. Contribuíram também negativamente dentro desse subgrupo o fato de a unidade não possuir processos descritos para verificação da qualidade do produto ou serviço adquirido e não definir metas de eficiência no gerenciamento dos fornecedores. É importante destacar que muitos desses campi do interior acabam por ter dificuldades na aquisição de bens e serviços numa qualidade compatível com as necessidade e quando acrescido o elemento da sustentabilidade percebe-se uma maior dificuldade.

O Campus Currais Novos apresentou resultado abaixo de $30 \%$ no critério "Processos de Prestação de Serviços", em que pesaram a ausência de campanhas de uso racional dos recursos como papel, combustíveis, telefone, materiais de consumo, ausência de processos de reciclagem dos resíduos, além de o campus - a exemplo dos outros dois - não premiar iniciativas internas que mitiguem os efeitos por ela causados ao meio ambiente. Colaborou também com o desempenho considerado fraco, o campus não ter definidas metas de eficiência energética. 
No critério "Responsabilidade Socioambiental" do Campus Currais Novos, observou-se que o baixo desempenho está relacionado à inexistência de uma política de comunicação sobre a responsabilidade ambiental e de um acompanhamento da satisfação da comunidade com a qual se relaciona, aliada a uma não sistematização da inclusão do tema nos projetos que desenvolve com essa comunidade. Tendo em vista o princípio constitucional da publicidade, a instituição deve promover a divulgação de suas ações. Por ter, a organização pública, como parte interessada a sociedade, e esta, em específico, tem como atividade-fim a educação, torna-se imperativo que lance mão dos meios disponíveis para comunicar suas ações de sustentabilidade ao público interno e externo e interagir com esses por meio de projetos. Em "Gestão da Instituição", a inexistência de um sistema de gestão ambiental ou plano de qualidade ambiental, bem como a ausência de processos definidos para medir sua eficiência ou os efeitos nocivos de suas atividades na sociedade e no ambiente são os destaques negativos mais importantes.

Quanto ao Campus Natal-Central, além do critério "Manutenção", apenas mais um teve desempenho na faixa "regular": o subgrupo "Contabilidade Gerencial e Auditoria Ambiental", que com $60 \%$ teve resultado próximo do limite inferior da faixa de desempenho "bom". Nesse subgrupo, o alcance de melhor resultado foi prejudicado pela existência de reclamações na Justiça do Trabalho nos últimos dois anos, por não definir metas e indicadores de eficiência para o acompanhamento das finanças. O Gráfico 1 representa a participação de cada critério ou subgrupo na constituição do índice de sustentabilidade de cada campi e no índice médio.

Gráfico 1 - Percentuais de contribuição dos subgrupos

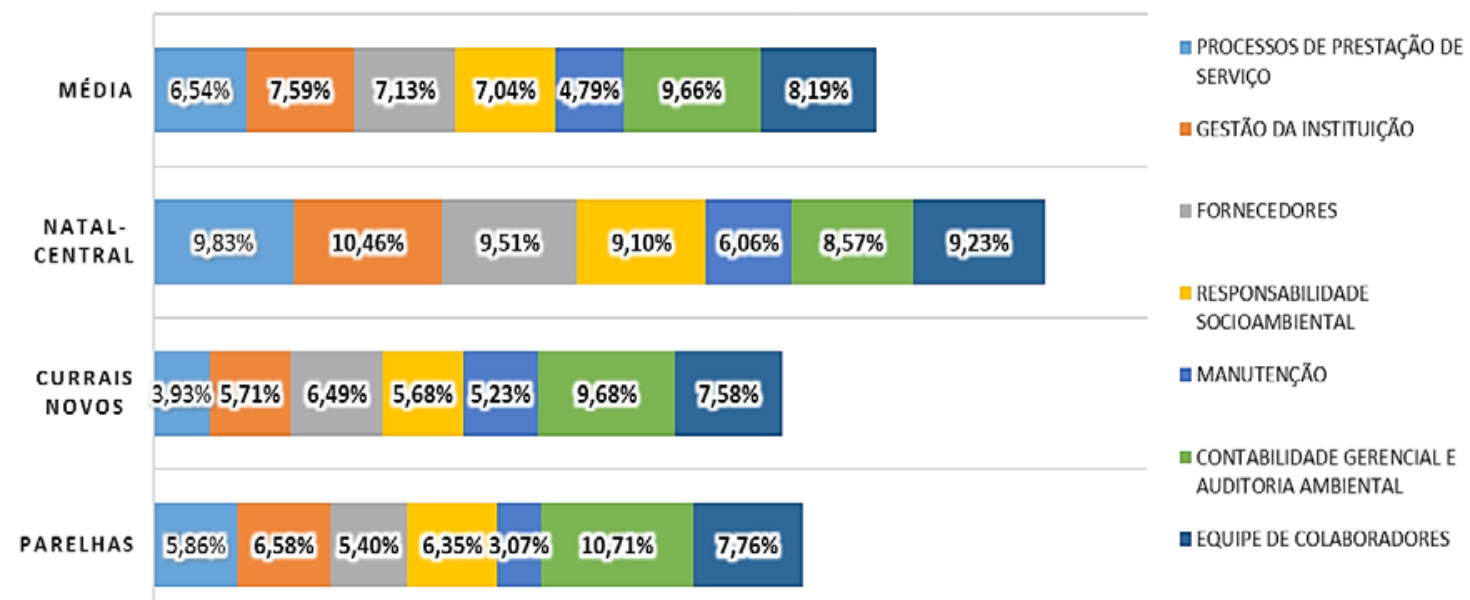

Fonte: Dados da pesquisa.

Percebe-se, no Campus Natal-Central, um maior equilíbrio entre as contribuições, à exceção do critério "Manutenção", com resultado mais fraco, como já mencionado. Apresentou uma amplitude nos percentuais de contribuição de $4,4 \%$, seguido pelo Campus Currais Novos, com 5,75\% de amplitude entre melhor e pior resultados dos critérios e, por último, o Campus Avançado de Parelhas, com 7,64\%.

Para melhor comparação entre os desempenhos foi elaborado, de forma adicional, o Gráfico 2, que enfatiza as diferenças de desempenho em cada campus por critério e demonstra, mediante as formas das figuras geradas pela interligação dos pontos (resultados dos critérios), as fragilidades e forças identificadas. 
Gráfico 2 - Comparação, entre os campi, das contribuições dos subgrupos

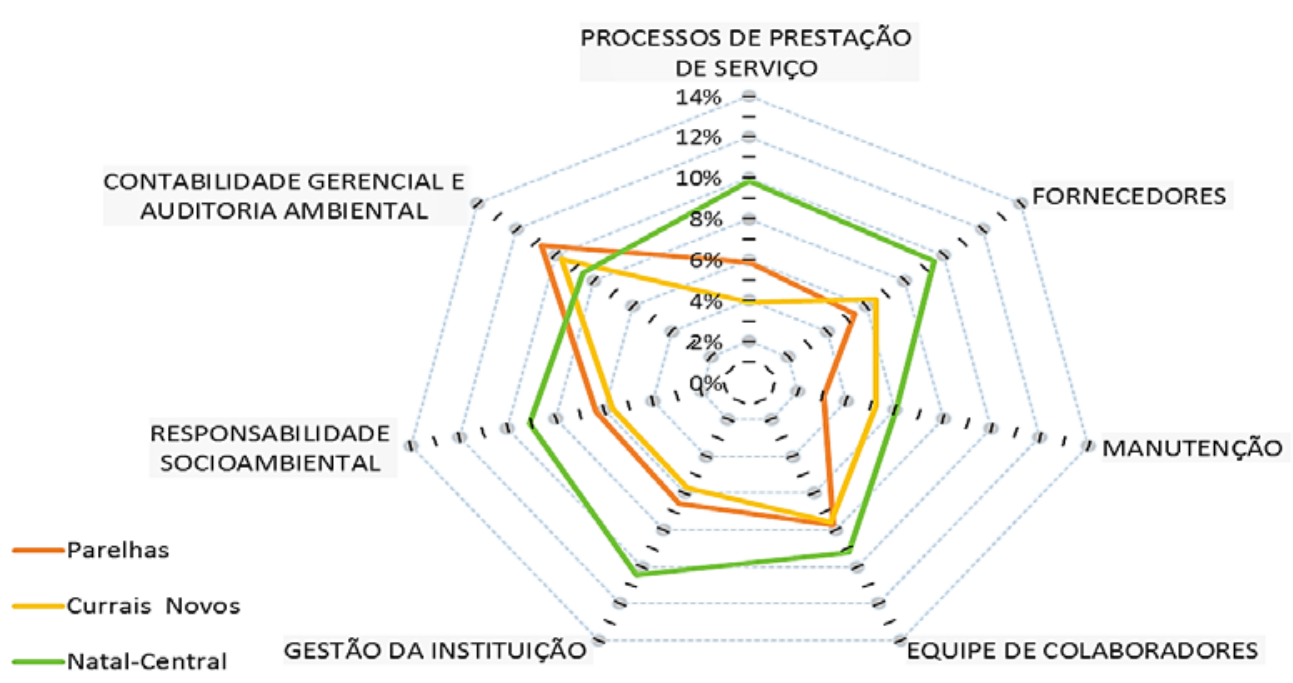

Fonte: Dados da pesquisa.

Como se pode visualizar no Gráfico 2, o Campus Natal-Central mostrou o meIhor desempenho entre os três. Percebe-se que os demais campi apresentam resultados mais baixos em sete dos critérios, superando-o apenas no critério "Contabilidade Gerencial e Auditoria Ambiental". O desempenho mais fraco deve-se à existência de passivos ambientais, de processos na Justiça do Trabalho e pela inexistência de metas e indicadores para finanças. Nesse tipo de gráfico, quanto mais regular a forma, mais equilibradas estariam os critérios quanto aos resultados. Dessa forma, a assimetria do gráfico, que se revela mais acentuada para os campi Parelhas e Currais Novos, evidencia que alguns critérios devem ser mais bem trabalhados, de forma a corrigir as distorções encontradas, alcançando um equilíbrio.

Com relação à amplitude de desempenhos dos campi, pode-se perceber uma maior extensão no critério "Processos de Prestação de Serviços", com 5,9\% de diferença entre os percentuais de contribuição do critério nos campi Currais Novos e Natal-Central. Essa discrepância está relacionada à diferença quanto à existência de campanhas de uso racional dos recursos como papel, combustíveis, telefone, materiais de consumo e de processos de reciclagem dos resíduos e quanto ao monitoramento da emissão de carbono e programas de compensação, itens em que o CNAT pontuou de forma importante. O subgrupo em que se observou menor discrepância foi o da "Equipe de Colaboradores", o que pode ser explicado pela existência de diversas perguntas cujas respostas não variam, por se tratarem de questões determinadas em lei ou, ainda, definidas sistemicamente, em resoluções do Conselho Superior, por exemplo, sem margem para alterações por parte dos campi. No Gráfico 3 apresentam-se os índices de sustentabilidade, representando o desempenho geral de cada um dos campi e da média, calculados a partir da soma dos percentuais de contribuição de cada critério. 


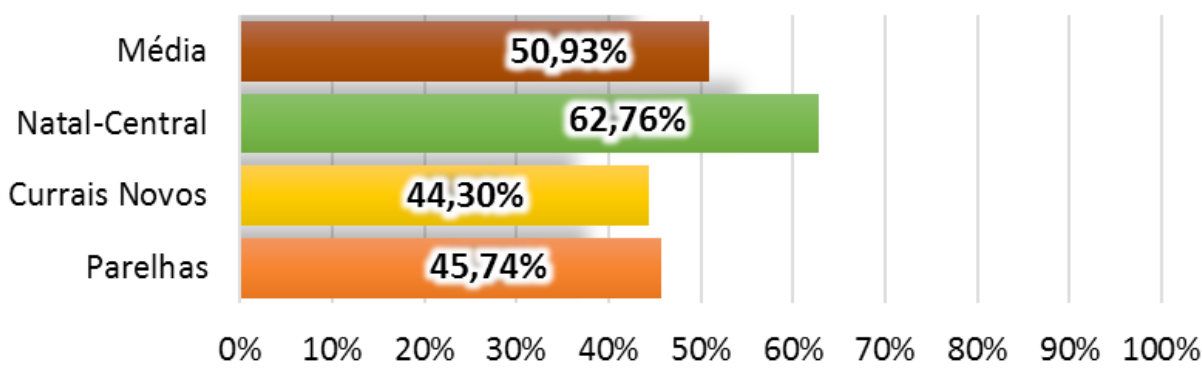

Fonte: Elaborado pelos autores a partir da pesquisa dos dados coletados.

Entre os três campi estudados, os índices de sustentabilidade apontaram para desempenho regular no Campus Avançado de Parelhas e no Campus Currais Novos e desempenho bom no Campus Natal-Central. O resultado do índice médio foi de $50.93 \%$, o que evidencia desempenho regular do conjunto dos campi. Este estudo constatou o esforço da instituição no sentido da redução do consumo e da produção de resíduos, da destinação correta dos resíduos sólidos, da produção de energia fotovoltaica, da captação e tratamento de água e do tratamento e reuso de efluentes líquidos. Por outro lado, observou-se que as ações ocorrem de maneira desarticulada, havendo recente sinalização de progresso na direção de uma sistematização dessas ações. Não há, em dois dos campi estudados, a presença de um sistema de gestão ambiental.

De acordo com Souza e Pfitscher (2013), esses sistemas são instrumentos de gestão que podem subsidiar a tomada de decisão. Importante destacar a necessidade do comprometimento da alta gestão de forma a respaldar a instituição do SGA e garantir de previsão orçamentária para as ações de sustentabilidade planejadas no âmbito desse sistema. Tendo em vista a adesão já realizada pelo IFRN, é oportuna a instalação da A3P, que se baseia na Norma Brasileira ABNT NBR ISO 14001/2004 - Sistema de Gestão Ambiental (MINISTÉRIO DO MEIO AMBIENTE, 2009) e adota indicadores de mensuração de desempenho para a elaboração de Relatórios Técnicos e definição de metas e ações de aperfeiçoamento (MINISTÉRIO..., 2015b).

Nos resultados foi verificado que não há uma normatização interna para a inclusão de critérios para compras e contratações sustentáveis, podendo causar falta de uniformidade nos critérios dos campi. A administração pública federal, por seu poder de compra estimula, a partir da adoção de critérios ecológicos, adequações do mercado em relação às exigências (SANTOS; FONSECA FILHO; FAGANELLO, 2015). Além disso, por força do Decreto no 7.746/2012, a administração pública federal deve adotar critérios, práticas e diretrizes em sustentabilidade nas suas contratações (BRASIL, 2012).

Foi possível observar interligação entre dois resultados com desempenho péssimo: o indicador relacionado à existência de processos de melhores práticas na área de gestão ambiental e o indicador que trata do incentivo a iniciativas internas que ofereçam soluções para minimizar os efeitos por ela causados ao meio ambiente. De acordo com Kraemer (2004), as Instituições de Ensino Superior devem promover, por meio de reflexão e da pesquisa acerca da concepção de soluções racionais, a conscientização acerca de problemas e soluções e tomar iniciativas. 


\section{CONSIDERAÇÕES FINAIS}

Este estudo buscou contribuir com uma análise da política de sustentabilidade do Instituto Federal de Educação, Ciência e Tecnologia do Rio Grande do Norte, evidenciando ações de sustentabilidade e o desempenho de três dos seus campi, especificamente na adaptação de uma ferramenta que possa apresentar um parâmetro para acompanhamento dos procedimentos dessa política, uma vez que é preciso monitorar o desenvolvimento de etapas de uma determinada política numa organização pública, o que não é comum no serviço público nacional e, especialmente, em instituições de ensino técnico e superior. A novidade deste estudo, portanto, foi justamente apresentar a possibilidade de acompanhar de forma mais concreta a gestão ambiental no ambiente público, e para isso foi escolhido o IFRN. Dessa forma, a estratégia de utilizar um sistema de indicadores mostrou-se positiva, porque evidenciou de maneira objetiva que as ações planejadas converteram-se em resultado positivo nos diversos aspectos relevantes.

A abordagem aqui apresentada apontou que o Instituto está perdendo uma imensa oportunidade ao não utilizar de maneira mais substancial o potencial latente existente nos cursos técnicos e superiores da área na produção de soluções de gestão ambiental para utilização nos seus campi. A atenção dada pelo Campus Currais Novos à captação e ao reuso da água é uma experiência que pode ser utilizada por outros campi, bem como o processo de compostagem realizado pelo Campus Natal-Central e a proteção dos prédios contra a radiação solar que reduz o consumo de energia do Campus Avançado de Parelhas. As soluções encontradas por essas unidades diante das demandas ambientais devem ser compartilhadas para que a troca de experiências ocorra. Evidenciou-se que não há esse compartilhamento interno, sendo possível potencializar e transformar a política de sustentabilidade da organização.

Na esteira da busca de analisar a política de sustentabilidade da organização, encontra-se a uma série de investimentos e iniciativas na busca por desenvolvimento sustentável numa perspectiva de gestão ambiental contemporânea, em contraponto a uma gestão carente de sistematização em cada um dos campi. Um dos principais desafios para uma organização pública do porte do IFRN, portanto, é estabelecer uma gestão que articule a sua Política de Gestão Ambiental, concebida recentemente, aos processos em níveis tático e operacional. Para isso é imprescindível a criação de um Sistema de Gestão Ambiental (SGA).

O funcionamento efetivo de um SGA, porém, depende do apoio e comprometimento da alta gestão da organização e dos campi no sentido de promover ou respaldar as mudanças necessárias nos processos, viabilizando também a formação (onde inexistem), a capacitação e dando condições de trabalho às Comissões de Meio Ambiente de cada campus. Assim, é preciso que além de um conteúdo da política de sustentabilidade bem articulado, construído, formulado, para que haja o engajamento precisa existir participação daqueles que fazem parte da organização, bem como acompanhamento de sua execução utilizando ferramentas que realizem a medição dos resultados. A alta gestão deve estar comprometida com a solução dos problemas que forem encontrados, de forma a garantir o investimento financeiro necessário para as medidas de controle que 
forem apontadas no âmbito dos programas. Os indicadores do Sicogea 2a Geração foram adequados aos objetivos da pesquisa pela sua abrangência e pela possibilidade de se obter resultados comparáveis mesmo se tratando de três campi de portes diferentes.

É oportuno o estabelecimento de uma relação justa com os colaboradores, o que passa, entre outros fatores, pela preservação e promoção da sua saúde e segurança. Esse assunto tem ganhado alguma atenção por parte da instituição, mas ainda há poucos efeitos práticos visíveis, refletindo nos resultados dos indicadores correspondentes. Uma possibilidade para futuras pesquisas é a avaliação utilizando os indicadores da A3P, que supostamente serão acompanhados pelos campi do IFRN, além da possibilidade de aplicação da mesma lista de verificação em outros campi, ou isso após uma suposta introdução de um Sistema de Gestão Ambiental nos que foram aqui avaliados, para uma comparação com esses resultados.

\section{REFERÊNCIAS}

ALMEIDA, R.; SCATENA, L. M.; LUZ, M. S. da. Percepção ambiental e políticas públicas - dicotomia e desafios no desenvolvimento da cultura de sustentabilidade. Ambient. Soc., São Paulo, v. 20, n. 1, p. 43-64, mar. 2017. Disponível em: <http://www.scielo.br/scielo.php?script=sci_arttext\&pi$\mathrm{d}=$ S1414-753X2017000100043\&Ing=en\&nrm=iso>. Acesso em: 11 oct. 2017. DOI: http://dx.doi.org/10.1590/1809-4422asoc20150004r1v2012017.

BECK, U. Sociedade de risco: rumo a uma outra modernidade. São Paulo: Editora 34, 2010.

BORELLA, M.; BARCELLOS, P.; BERTOLAZZI, M. O clima ético das organizações e a temática do meio ambiente. In: Rev. Portuguesa e Brasileira de Gestão [on-line], vol. 10, n. 3, p. 2-13, 2011.

BORGES, A. F. et al. Análise da gestão ambiental nos institutos federais de educação, ciência e tecnologia. Cerne, Lavras, v. 19, n. 2, p. 177-184, abr./jun. 2013.

BRASIL. Decreto no 7.746, de 5 de junho de 2012. Regulamenta o art. 30 da Lei no 8.666, de 21 de junho de 1993, para estabelecer critérios, práticas e diretrizes para a promoção do desenvolvimento nacional sustentável nas contratações realizadas pela administração pública federal, e institui a Comissão Interministerial de Sustentabilidade na Administração Pública - CISAP. Diário Oficial da União, Brasília, DF, 6 jun. 2002. Seção 1. Disponível em: <http://www.planalto.gov.br/ccivil_03/_ato2011-2014/2012/decreto/ d7746.htm>. Acesso em: 23 jul. 2015.

Lei no 11.892 de 29 dezembro 2008. Institui a Rede Federal de Educação Profissional, Científica e Tecnólogica, cria os institutos federais de educação, ciência e tecnologia, e dá outras providências. Diário Oficial da União, Brasília, DF, 30 dez. 2008. Seção 1. Disponível em: <http://www.planalto.gov.br/ ccivil_03/_ato2007-2010/2008/lei/l11892.htm>. Acesso em: 30 maio 2016.

Lei no 12.349, de 15 de dezembro de 2010. Altera as Leis nos 8.666, de 21 de junho de 1993, 8.958, de 20 de dezembro de 1994, e 10.973, de 2 de dezembro de 2004; e revoga o $\S 10$ do art. 20 da Lei no 11.273, de 6 de fevereiro de 2006. Diário Oficial da União, Brasília, DF, 16 dez. 2010. Seção 1. Disponível em: <http:// www.planalto.gov.br/ccivil_03/_Ato2007-2010/2010/Lei/L12349.htm>. Acesso em: 20 jul. 2015.

Lei no 6.938, de 31 de agosto de 1981. Dispõe sobre a Política Nacional do Meio Ambiente, seus fins e mecanismos de formulação e aplicação, e dá outras providências. Diário Oficial da União, Brasília, DF, 2 set. 1981. Seção 1. Disponível em: <http://www.planalto.gov.br/ccivil_03/Leis/ L6938.htm>. Acesso em 20 jul. 2015.

CAMARGO, J. A.; LIBONI, L. B.; OLIVEIRA, J. H. C. de. Gestão ambiental de recursos humanos e nível de envolvimento de colaboradores nas organizações. In: RAM, Rev. Adm. Mackenzie, 16(2), p. 72-91, 2015.

CARVALHO, L. V. B. et al. Exposição ocupacional a substâncias químicas, fatores socioeconômicos e saúde do trabalhador: uma visão integrada. Saúde debate, Rio de Janeiro, v. 41, n. especial 2, p. 313-326, jun. 2017. Disponível em: <http://www.scielo.br/scielo.php?script=sci_arttext\&pid=S0103-11042017000600313\&Ing=en\&nrm=iso>. Acesso em: 11 oct. 2017. DOI: http://dx.doi. org/10.1590/0103-11042017s226.

CASTRO, L. S. P. de; MONTEIRO, J. K. Fumicultores advertem: a causa do seu sofrimento é a exploração no trabalho. Psicol. Soc., Belo Horizonte, v. 27, n. 1, p. 87-97, abr. 2015. Disponível em: <http://www.scielo.br/scielo.php?script=sci_arttext\&pid=S0102-71822015000100087\&lng=en\&nrm=iso>. Acesso em: 11 oct. 2017. DOI: http://dx.doi.org/10.1590/1807-03102015v27n1p087. 
COMISSÃO MUNDIAL SOBRE MEIO AMBIENTE E DESENVOLVIMENTO (CMMAD). Nosso futuro comum. 1987. Disponível em: <http://www.un-documents.net/wced-ocf.htm>. Acesso em: 12 mar. 2015. DIZDAROGLU, D.; YIGITCANLAR, T. Ecological approaches in planning for sustainable cities a review of the literature. In: Global J. Environ. Sci. Manage., 1(2): p. 159-188, Spring 2015.

FERNANDES, M. Desenvolvimento sustentável: antinomias de um conceito. In: FERNANDES, M.; GUERRA, L. (Org.). Contra-discurso do desenvolvimento sustentável. Belém: Unamaz, 2003.

FERNANDEZ, Carlos F. Lascurain. Análisis de La Política Ambiental. México: Plaza y Valdés, 2006.

FERREIRA, C. dos S.; GEROLAMO, M. C. Análise da relação entre normas de sistema de gestão (ISO 9001, ISO 14001, NBR 16001 e OHSAS 18001) e a sustentabilidade empresarial. Gest. Prod., São Carlos, v. 23, n. 4, p. 689-703, dez. 2016. Disponivel em: <http://www.scielo.br/scielo.php?script=sci_arttext\&pid=S0104-530X2016000400689\&lng=en\&nrm=iso>. Acesso em: 11 oct. 2017. DOI: http://dx.doi. org/10.1590/0104-530x2525-15.

FREIRE, P. A. Assédio moral e saúde mental do trabalhador. Trab. Educ. Saúde, Rio de Janeiro, v. 6, n. 2, p. 367-380, out. 2008. Disponível em: <http://www.scielo.br/scielo.php?script=sci_arttext\&pi$d=$ S1981-77462008000200009\&lng=en\&nrm=iso>. Acesso em: 11 oct. 2017. DOI: http://dx.doi. org/10.1590/S1981-77462008000200009.

FREITAS, C. L. Avaliação de sustentabilidade em Instituições Públicas Federais de Ensino Superior (IFES): proposição de um modelo baseado em sistemas gerenciais de avaliação e evidenciação socioambiental. 2013. Dissertação (Mestrado em Contabilidade) - UFSC, Florianópolis, 2013.

FURTADO, J. S. Sustentabilidade empresarial: guia de práticas econômicas, ambientais e sociais. Salvador: Neama/CRA, 2005.

GAUDIANO, E. G. Educación ambiental: trayectorias, rasgos y escenarios. México: Plaza y Valdés, 2007.

GOMES, C. A.; FRANCO, R.; CALADO, D. Energias renováveis em Portugal: evolução e perspectivas. e-Pública, Lisboa, v. 1, n. 1, p. 365-398, jan. 2014. Disponível em: <http://www.scielo.mec.pt/scielo.php?scrip$\mathrm{t}=\mathrm{sci}$ arttext\&pid=S2183-184X2014000100017\&lng=pt\&nrm=iso>. Acesso em: 11 out. 2017.

INSTITUTO FEDERAL DE EDUCAÇÃO, CIÊNCIA E TECNOLOGIA DO RIO GRANDE DO NORTE (IFRN). Aprovar, na forma do anexo, o Regimento Interno do Núcleo de Estudos Afro-Brasileiros e Indígenas (NEABI) do Intituto Federal de Educação, Ciência e Tecnologia do Rio Grande do Norte. Deliberação no 17/2011 - CONSEPEX/IFRN de 25 de novembro de 2011. Disponível em: <http://portal.ifrn.edu.br/conselhos/consepex/ deliberacoes/2011/deliberacao-no-17-2011/at_download/file>. Acesso em: 10 maio 2016.

Campus Pau dos Ferros do IFRN recebe usina fotovoltaica. 2016. Disponível em: <http://portal. ifrn.edu.br/campus/paudosferros/noticias/campus-pau-dos-ferros-do-ifrn-recebe-usina-fotovoltaica>. Acesso em: 10 maio 2016.

Plano de logística sustentável. Natal, 2013. Disponível em: <http://portal.ifrn.edu.br/servidores/ campus-verde/plano-logistica-sustentavel/at_download/file>. Acesso em: 4 abr. 2016.

Resolução № 08/2015-CONSUP, de 13 de março de 2015a. Dispõe sobre a Política Socioambiental do Instituto Federal de Educação, Ciência e Tecnologia do Rio Grande do Norte. Disponível em: <http:// portal.ifrn.edu.br/conselhos/consup/resolucoes/2015/resolucao-no-08-2015/at_download/file>. Acesso em: 4 abr. 2016.

Resolução № 16/2015-CONSUP, de 12 de junho de 2015b. Cria e regulamenta as Comissões Internas de Saúde do Servidor Público - CISSP - no âmbito do Instituto Federal do Rio Grande do Norte. Disponível em: <http://portal. ifrn.edu.br/conselhos/consup/resolucoes/2015/resolucao-no-16-2015/ at_download/file>. Acesso em: 10 maio 2016.

KRAEMER, M. E. P. A Universidade do século XXI rumo ao desenvolvimento sustentável. Revista Eletrônica de Ciência Administrativa (RECADM), v. 3, n. 2, nov. 2004.

KRUGER, S. D. et al. Sustentabilidade ambiental: estudo em uma instituição de ensino catarinense. Sociedade, Contabilidade e Gestão, Rio de Janeiro, v. 8, n. 1, jan./abr. 2013.

LEITE, S. P.; DELGADO, N. G. Desenvolvimento territorial rural no Brasil: políticas públicas, atores e sustentabilidade. In: Revista Dados, vol. 54, n. 1, 2001. Disponível em: <http://www.congressorio20.org.br/sitio/ images/stories/pdf/sergio-pereira.pdf>. Acesso em: 11 dez. 2016.

LENZI, C. L. Sociologia ambiental: risco e sustentabilidade na modernidade. Bauru, SP: Edusc, 2006.

LOIZIDOU, M. D.; OGLANIS, A. A. Study of environmental management systems on defence. In: Global J. Environ. Sci. Manage., 3(1), p. 103-120, Winter 2017. 
LOUREIRO, C. F.; COSTA, C. A. A interdisciplinaridade em Paulo Freire: aproximações político-pedagógicas para a educação ambiental crítica. Rev. Katálysis, Florianópolis, v. 20, n. 1, p. 111-121, abr. 2017. Disponível em: <http://www.scielo.br/scielo.php?script=sci_arttext\&pid=S1414-49802017000100111\&Ing=en\&nrm=iso>. Acesso em: 11 oct. 2017. DOI: http://dx.doi. org/10.1590/1414-49802017.00100013.

LUIZ, L. et al. Inclusão de práticas ambientais nas auditorias realizadas no âmbito de uma instituição federal de educação. Revista de Gestão Ambiental e Sustentabilidade - GeAS, v. 3, n. 2, p. 92-112, ago. 2014.

MENDES, J. N. A política energética no contexto das dinâmicas globais. Relações Internacionais, Lisboa, n. 28, p. 133-138, dez. 2010. Disponível em: <http://www.scielo.mec.pt/scielo.php script=sci_arttext\&pi$\mathrm{d}=\mathrm{S} 1645-91992010000400010 \&$ Ing=pt\&nrm=iso>. Acesso em: 11 out. 2017.

MINAYO-GOMEZ, C.; BARATA, M. M. de L.; KLIGERMAN, D. C. A gestão ambiental no setor público: uma questão de relevância social e econômica. Ciênc. saúde coletiva, Rio de Janeiro, v. 12, n. 1, p. 165-170, mar. 2007. Disponível em: <http://www.scielo.br/scielo.php?script=sci_arttext\&pi$\mathrm{d}=\mathrm{S} 1413-81232007000100019 \& \mid n g=e n \& n r m=i s o>$. Acesso em: 11 oct. 2017. DOI: http://dx.doi. org/10.1590/S1413-81232007000100019.

MINISTÉRIO DA EDUCAÇÃO (MEC). Mulheres Mil - O que é. 2008. Disponível em: <http://mulheresmil. mec.gov.br/o-que-e-44388>. Acesso em: 28 abr. 2016.

MINISTÉRIO DO MEIO AMBIENTE (MMA). Agenda ambiental na administração pública. 5. ed. Brasília: MMA; SAIC; DCRS; Comissão Gestora da A3P, 2009. 100p.

Adesão à A3P. Disponível em: <http://www.mma.gov.br/responsabilidade-socioambiental/a3p/ adesão-à-a3p >. Acesso em: 29 mar. 2015a.

Indicadores A3P. Disponível em: <http://www.mma.gov.br/images/arquivo/ 80063/cartilha\%20 completa\%20A3P.pdf>. Acesso em: 23 jul. 2015b.

Parceiros com Adesão à Rede A3P. Disponível em: <http://www.mma.gov.br/component/k2/ item/10326-parceiros-com-adesao-a-rede-a3p>. Acesso em: 12 dez. 2015c.

MINISTÉRIO do PLANEJAMENTO, ORÇAMENTO E GESTÃO (MPOG). Portaria no. 23, de 12 de fevereiro de 2015. Estabelece boas práticas de gestão e uso de energia elétrica e de água nos órgãos e entidades da administração pública federaldireta, autárquica e fundacional e dispõe sobre o monitoramento de consumo desses bens e serviços. Disponível em: <https://conlegis.planejamento.gov.br/conlegis/Downloads/ file?PORTARIA\%20N\%BA\%2023\%20-\%202015.pdf>. Acesso em: 14 dez 2015.

NUNES, J. P. O. Um aporte ao sistema contábil gerencial ambiental: elaboração e aplicação parcial do novo sistema em clínica hospitalar. 2010, 241 f. Dissertação (Mestrado) - Programa de Pós-Graduação em Contabilidade, Universidade Federal de Santa Catarina, Florianópolis, 2010.

PACHANA, N. A. et al. Relations between companion animals and sel-reported health in older women: cause, effect ou artifact? International Journal of Behavioral Medicine, 12, 103, 2005.

PAULINO, S.; CRUZ, S. Public Service Innovation and Evaluation Indicators. In: J. Technol. Manag. Innov., 2013, volume 8, Special Issue Altec, 2013.

PFITSCHER, E. D. Gestão e sustentabilidade através da contabilidade e controladoria ambiental: estudo de caso na cadeia produtiva de arroz ecológico. 2004. Tese (Doutorado) - Universidade Federal de Santa Catarina, Centro Tecnológico, Programa de Pós-Graduação em Engenharia de Produção, Florianópolis, 2004.

PINTO, R. A. de F. R.; MONDELLI, G. Potencial de recuperação de recicláveis em um condomínio residencial de grande porte de São Caetano do Sul. Eng. Sanit. Ambient., Rio de Janeiro, v. 22, n. 4, p. 647-656, ago. 2017. Disponível em: <http://www.scielo.br/scielo.php?script=sci_arttext\&pi$\mathrm{d}=$ S1413-41522017000400647\&lng=en\&nrm=iso>. Acesso em: 11 out. 2017. DOI: http://dx.doi. org/10.1590/s1413-41522017146383.

PIRES, M. A. et al. Valorização do tema "Responsabilidade Social" em Instituições de Ensino Superior? Análise de cursos de Administração no Estado do Rio de Janeiro. Cad. EBAPE.BR, Rio de Janeiro, v. 15, n. especial, p. 462-481, set. 2017. Disponível em: <http://www.scielo.br/scielo.php?script=sci_arttex t\&pid=S1679-39512017000700462\&lng=en\&nrm=iso>. Acesso em: 11 out. 2017. DOI: http://dx.doi. org/10.1590/1679-395160284.

PROGRAMA ÁGUA AZUL. O Programa. Disponível em: <http://programaaguaazul.rn.gov.br/sobre/programa>. Acesso em: 23 maio 2016.

RATTO, C. G.; HENNING, P. C.; ANDREOLA, B. A. Educação ambiental e suas urgências: a constituição de uma ética planetária. Educ. Real., Porto Alegre, v. 42, n. 3, p. 1.019-1.034, jul. 2017. Disponível em: <http://www.scielo.br/scielo.php?script=sci_arttext\&pid=S2175-62362017000301019\&lng=en\&nrm=iso>. Acesso em: 11 out. 2017. DOI: http://dx.doi.org/10.1590/2175-623659438. 
REDCLIFT, M. R. Pós-sustentabilidade e os novos discursos de sustentabilidade. In: Raízes, Campina Grande, vol. 21, n. 1, p. 124-136, jan./jun. 2002.

ROCHA, S.; PFITSCHER, E.; CARVALHO, F. Sustentabilidade ambiental: estudo em uma instituição de ensino superior pública catarinense. Revista de Gestão Ambiental e Sustentabilidade - GeAS, v. 4, n. 1, p. 46-58, jan. 2015.

. Caminhos para o desenvolvimento sustentável. Rio de Janeiro: Garamond, 2009. 96 p.

Desenvolvimento: includente, sustentável, sustentado. Rio de Janeiro: Garamond, 2008.

SACHS, I. Caminhos para o desenvolvimento sustentável. 3. ed. Rio de Janeiro: Garamond, 2008.

SANTOS, A. R. A.; FONSECA FILHO, L. F.; FAGANELLO, C. R. F. Práticas de compras públicas sustentáveis na Universidade Federal do Recôncavo da Bahia. Campo Jurídico, vol. 3, n. 1, p. 15-51, maio 2015.

SILVA, J. I. A. O. A dimensão ambiental como política pública e condicionante para o desenvolvimento. In: MELO, Clóvis Alberto Vieira de; SOARES, Kelly Cristina Costa. Instituições, gestão pública e desenvolvimento: perfil socioeconômico e político do Cariri Paraibano. Recife: Ed. Nossa Livraria, 2011. p. 247-288.

SOUZA, P.; PFITSCHER, E. D. Gestão e sustentabilidade ambiental: estudo em um órgão público do Estado de Santa Catarina. Revista de Contabilidade e Controladoria, Curitiba: Universidade Federal do Paraná, v. 5, n. 3, p. 8-32, set./dez. 2013. ISSN 1984-6266.

SOUZA, M. T. S. et al. Estudo bibliométrico de teses e dissertações em administração na dimensão ambiental da sustentabilidade. REAd. Rev. Eletrôn. Adm., Porto Alegre, v. 19, n. 3, p. 541-568, dec. 2013. Disponível em: $<$ http://www.scielo.br/scielo.php?script=sci_arttext\&pid=S1413-23112013000300001\&lng=en\&nrm=iso>. Acesso em: 11 out. 2017. DOI: http://dx.doi.org/10.1590/S1413-23112013000300001.

SUSHIL, A. S. Developing a conceptual framework of waste management in the organizational context, Management of Environmental Quality. In: An International Journal, vol. 28, n. 6, p. 786-806, 2017. DOI: https://doi.org/10.1108/MEQ-07-2016-0045.

TAUCHEN, J.; BRANDLI, L. L. A gestão ambiental em instituições de ensino superior: modelo para implantação em campus universitário. Gestão \& Produção, v. 13, n. 3, p. 503-515, set./dez. 2006.

TEIXEIRA, M. G. C.; AZEVEDO, L. P. A agenda ambiental pública: barreiras para a articulação entre critérios de sustentabilidade e as novas diretrizes da administração pública federal brasileira. REAd. Rev. Eletrôn. Adm., Porto Alegre, v. 19, n. 1, p. 139-164, abr. 2013.

VAZ, C. R. et al. Sistema de gestão ambiental em instituições de Ensino Superior: uma revisão. Gepros. Gestão da Produção, Operações e Sistemas, ano 5, n. 3, p. 45-58, 2010.

WARKEN, I. L. M.; HENN, V. J.; ROSA, F. S. Gestão da sustentabilidade: um estudo sobre o nível de sustentabilidade socioambiental de uma instituição federal de ensino superior. Revista de Gestão, Finanças $e$ Contabilidade, v. 4, n. 3, p. 147-166, 2014.

WARKEN, I. L. M.; KLANN, R. C. Sustentabilidade ambiental: um estudo sob a perspectiva da teoria institucional. Revista Contabilidad y Negocios, v. 9, p. 99-113, 2014. 